\title{
Imaging of a $\beta$-Peptide Distribution in Whole-Body Mice Sections by MALDI Mass Spectrometry
}

\author{
Markus Stoeckli, ${ }^{\text {a }}$ Dieter Staab, ${ }^{\text {a }}$ Alain Schweitzer, ${ }^{\mathrm{b}}$ James Gardiner, ${ }^{\mathrm{c}}$ \\ and Dieter Seebach ${ }^{\mathrm{c}}$ \\ ${ }^{a}$ Novartis Institutes for BioMedical Research, Basel, Switzerland \\ ${ }^{\mathrm{b}}$ Exploratory Development, Drug Metabolism, and Pharmacokinetics, Novartis, Basel, Switzerland \\ ${ }^{c}$ Laboratory for Organic Chemistry, Department of Chemistry and Biosciences, ETH-Zürich, Zürich, \\ Switzerland
}

\begin{abstract}
Mass spectrometric imaging was applied to assess compound distributions on whole-body sections of mice after i.v. dosing of a $\beta$-peptide and an $\alpha$-peptide control. Animals were sacrificed at different time points $(5 \mathrm{~min}, 1 \mathrm{~h}, 24 \mathrm{~h}$ ) post-dose, providing simultaneous spatial as well as kinetic information. As a result of this study, no detection of the $\alpha$-peptide control was observed at $1 \mathrm{~h}$ post-dose, while retention of the $\beta$-peptide was observed for longer than $24 \mathrm{~h}$ post-dose. (J Am Soc Mass Spectrom 2007, 18, 1921-1924) (C) 2007 American Society for Mass Spectrometry
\end{abstract}

$\mathrm{M}$ atrix-assisted laser desorption/ionization (MALDI) mass spectrometric imaging (MSI) [1] is a novel molecular imaging method, which has already proven its value in numerous studies, including measurement of neuropeptides [2-4] in mouse brain sections and small organic compound distributions measured on whole-body tissue sections [5, 6]. However, the full potential of this method still remains to be explored.

One area of interest is that of $\beta$-peptides, oligomers of $\beta$-amino acids that adopt stable secondary structures (helices, sheets, or turns) in solution with as few as 4 to 6 residues [7]. $\beta$-Peptides display potent biological activity in many cases, i.e., somatostatin mimics [8], and are stable to proteases and peptidases, a feature not generally shared by their $\alpha$-peptidic counterparts [9]. Previous absorption, distribution, metabolism, and excretion (ADME) studies in rats have shown $\beta$-peptides to be metabolically stable and to display tissue specific distribution [10]. It is therefore of intense interest to continue the study of the in vivo properties of $\beta$-peptides if they are to be pursued as potential drug candidates. Since radio- or isotopic-labeling of compounds can often be tedious and expensive, we postulated that mass spectrometry techniques could be used to determine the tissue distribution of such parent compounds without the need for labeling. MS techniques have also been successfully used previously for the sequencing of $\beta$-peptides [11]. As such, we envisaged using MS and the unique

Address reprint requests to Dr. M. Stoeckli, Novartis Institutes for BioMedical Research, Lichtstrasse 35, 4056 Basel, Switzerland. E-mail: markus. stoeckli@novartis.com properties of $\beta$-peptides to visualize their distribution over time in animal tissue in a way not possible with $\alpha$-peptides. With the high sensitivity of MALDI MS in the peptide mass range, it is an obvious choice to apply MALDI MS imaging to the study of the distribution of $\beta$-peptides as reported here. We therefore chose two peptides (Figure 1), formerly used in the study of class 1 MHC peptide mimics, as representative examples of a $\beta$ - and an $\alpha$-peptide [12].

\section{Experimental}

$\beta$-Peptide 1 (H- $\beta^{3}$ hGly-(S) $\beta^{3}$ hArg- $(S) \beta^{3}$ hAla- $(S) \beta^{3}$ hAla(R) $\beta^{3}$ hAla- $(S) \beta^{3}$ hAla- $(R) \beta^{3}$ hAla- $(S) \beta^{3}$ hLys-OH) was prepared by solid-phase-peptide-synthesis according to [12]. $\alpha$-Peptide 2 (Rheuma peptide Ser-Arg-His-His-Ala-PheCys-Phe-Arg) was purchased from NeoMPS (San Diego, CA).

Three HLA-B27 transgenic mice were dosed intravenously (via injection into the tail vein) with $0.5 \mathrm{~mL}$ of a $2 \mathrm{mg} / \mathrm{mL}$ saline solution of $\beta$-peptide 1 . A fourth mouse was dosed with $0.5 \mathrm{~mL}$ of a $2 \mathrm{mg} / \mathrm{mL}$ saline solution of the Rheuma $\alpha$-peptide 2 as a control. Mice treated with $\beta$-peptide 1 were sacrificed at $5 \mathrm{~min}, 1 \mathrm{~h}$, and $24 \mathrm{~h}$ post-dose (one mouse per time point) and immediately deep frozen vertically in a mixture of dry-ice and $\mathrm{N}$-hexane at a temperature of $-75^{\circ} \mathrm{C}$ to limit the risk of post-mortem diffusion of the drug. The mouse treated with $\alpha$-peptide 2 was sacrificed $1 \mathrm{~h}$ post-dose and frozen in an identical manner. Slow immersion prevented cracking of the animals in the abdominal region, a phenomenon often observed due to freezing shock. The animals were left in the 

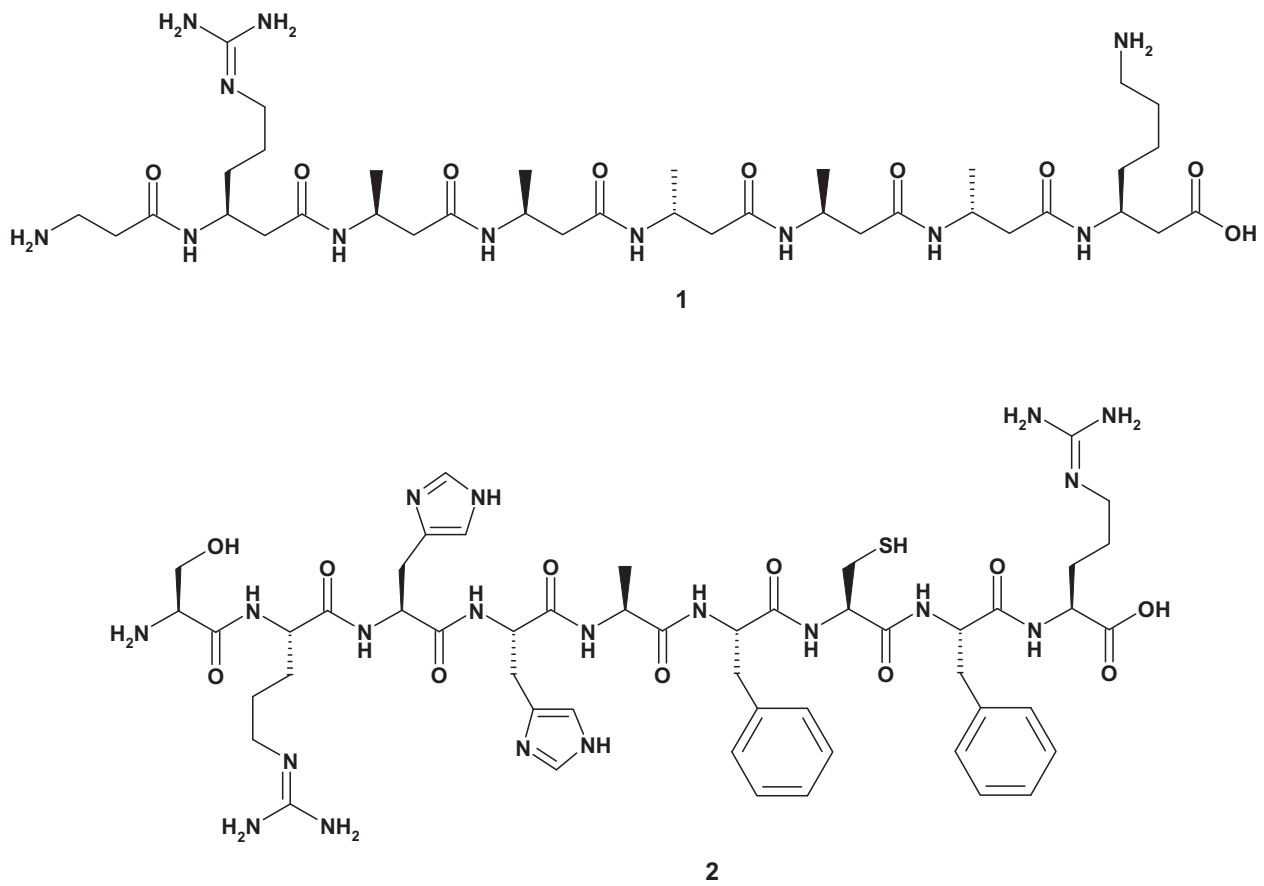

Figure 1. Peptides used in this study: $\beta$-peptide $1\left(\mathrm{H}-\beta^{3} \mathrm{hGly}-(S) \beta^{3} \mathrm{hArg}-(S) \beta^{3} \mathrm{hAla}-(S) \beta^{3} \mathrm{hAla}-\right.$ (R) $\beta^{3}$ hAla- $(S) \beta^{3}$ hAla- $(R) \beta^{3}$ hAla- $(S) \beta^{3}$ hLys-OH) and $\alpha$-peptide 2 (Rheuma peptide Ser-Arg-His-HisAla-Phe-Cys-Phe-Arg).

freezing mixture for 30 to $40 \mathrm{~min}$; thereafter, the excess of the dry-ice/hexane mixture was rapidly removed with the help of paper tissues before embedding the mice in a semi-liquid gel of $2 \%$ sodium carboxy-methyl-cellulose pre-cooled to $-75^{\circ} \mathrm{C}$. Sagittal sections of $40 \mu \mathrm{m}$ thickness were obtained at $-20{ }^{\circ} \mathrm{C}$ in a CM 3600 PLC cryomicrotome (Leica Microsystems, Nussloch, Germany) according to the method of Ullberg [13]. The sections were rapidly freeze-dried in a desiccator, and each section was mounted onto two adjacent metal sample plates fitting into the mass spectrometer. Matrix coating was obtained by spraying $4 \mathrm{~mL}$ per plate of a solution of $10 \mathrm{mg} / \mathrm{mL}$ CHCA in 50:50 acetonitrile/water using a TLC sprayer. The plates were dried for another hour in the desiccator before analysis.

MS Image acquisition was conducted on a 4700 Proteomics Analyzer (Applied Biosystems, Framingham, MA) equipped with an automatic plate loader for multiple plates. Each plate was rastered over in a 0.5 $\mathrm{mm} \times 0.5 \mathrm{~mm}$ grid while acquiring reflectron spectra from 100 laser shots of each position in the mass range from $\mathrm{m} / \mathrm{z} 200$ to 2000. The two images of each animal section were combined and analyzed in the BioMap software (http://www.maldi-msi.org). For each section, an ion intensity image was calculated for the protonated $\left([\mathrm{M}+\mathrm{H}]^{+}, m / z 827\right)$, sodiated $\left([\mathrm{M}+\mathrm{Na}]^{+}\right.$, $m / z$ 849), and potassiated $\left([\mathrm{M}+\mathrm{K}]^{+}, m / z\right.$ 865) species. The heme distribution $(\mathrm{m} / \mathrm{z}$ 616) was calculated for quality control.

\section{Results and Discussion}

The mass spectrum shown in Figure 2 was acquired from the kidney region of a mouse treated with the $\beta$-peptide. Strong signals are detected for the protonated species as well as for the metal adducts. Figure 3 shows the mass spectrometric images of the $\beta$-peptide species combined with the heme distribution and an optical image of the sections before matrix coating. The color scale was kept constant for all the peptide images. In the first time point, $5 \mathrm{~min}$ after administration, $\beta$-peptide 1 is detected in the section, with the corresponding sodium and potassium adducts accounting for a major part of the signal intensity. At $1 \mathrm{~h}$ post-dose, the $\beta$-peptide is observed being excreted through the kidney with signals from the released urine clearly visible in the images (lower left). The animal sacrificed at the final time point, $24 \mathrm{~h}$ post-dose, still exhibits detectable $\beta$-peptide concentrations (as the potassiated adduct) in the kidney. This result is in good agreement with those obtained in previous ADME experiments [10] in which it was shown that similar radiolabeled $\beta$-peptides exhibit proteolytic and metabolic stabilities in vivo [10] and prolonged tissue-specific half lives. In contrast to $\beta$-peptide 1, sections obtained $1 \mathrm{~h}$ post-dose from the animal dosed with 2 showed no trace of the $\alpha$-peptide, indicating that it had been quickly degraded in the circulatory system by peptidases in the blood and oxidative enzymes in the liver and kidneys (Figure 2). This clearly demonstrates that $\beta$-peptides, and similar 


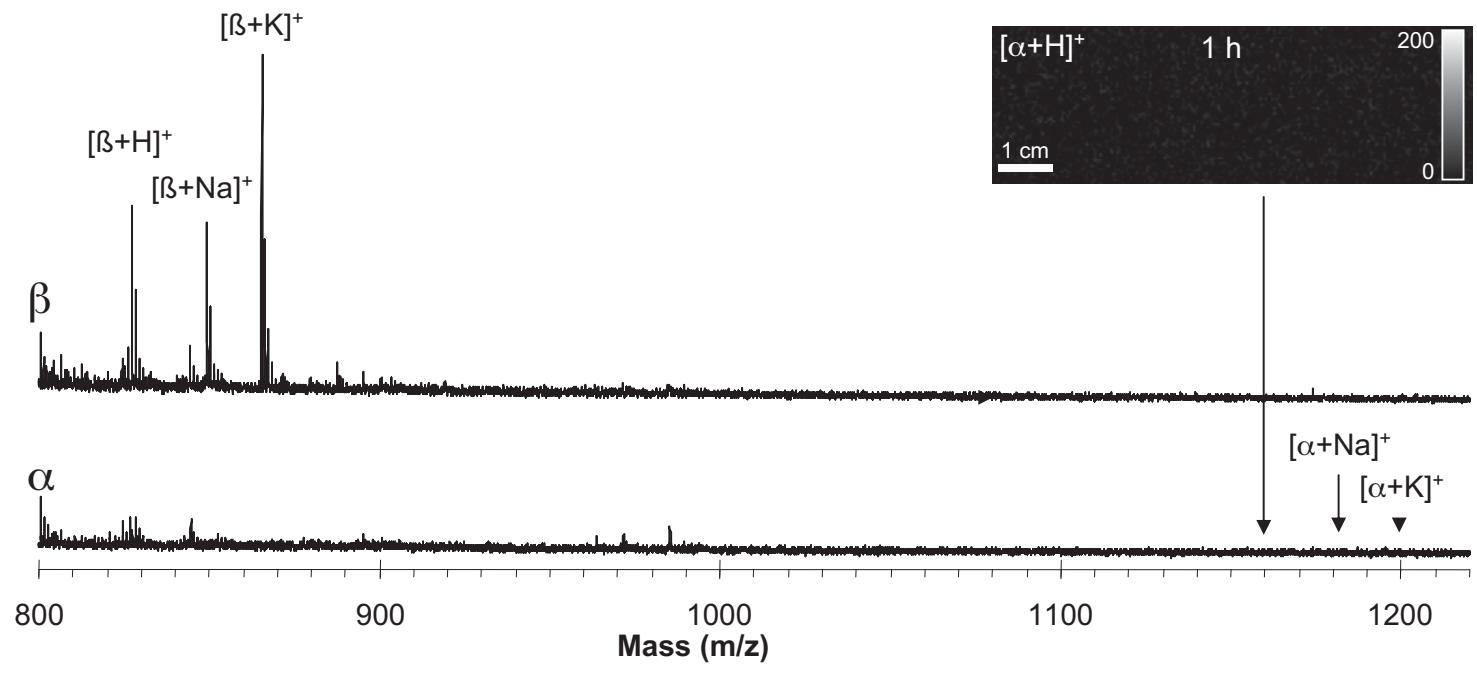

Figure 2. Mass spectra obtained directly from the kidney region of tissue sections of animals dosed with $\beta$-peptide (top) and $\alpha$-peptide (bottom). The mass spectrometric image of the $\alpha$-peptide distribution $1 \mathrm{~h}$ post-dose is shown as control. The $\alpha$-peptide is readily processed and was therefore not detectable.

peptidomimetics, can be visualized using MALDI-MSI to determine tissue distribution in a manner similar to that obtained by whole body autoradioluminography (WBAL). The overall sensitivity of MALDI-MSI depends strongly on the tissue and on the peptide. In this study, the detection limits for the two peptides were not exactly determined. However, tissue spiking experiments showed the lower limit of detection to be in the range of nanomo- lar concentrations, which is in agreement with previously published peptide work [4].

These results also match well with the outcome of a previous study on a similar peptide where the peptide distribution was determined by whole-body autoradiography [10]. Since the matrix deposition involves a manual step, ion intensities of the high abundant heme group are compared.
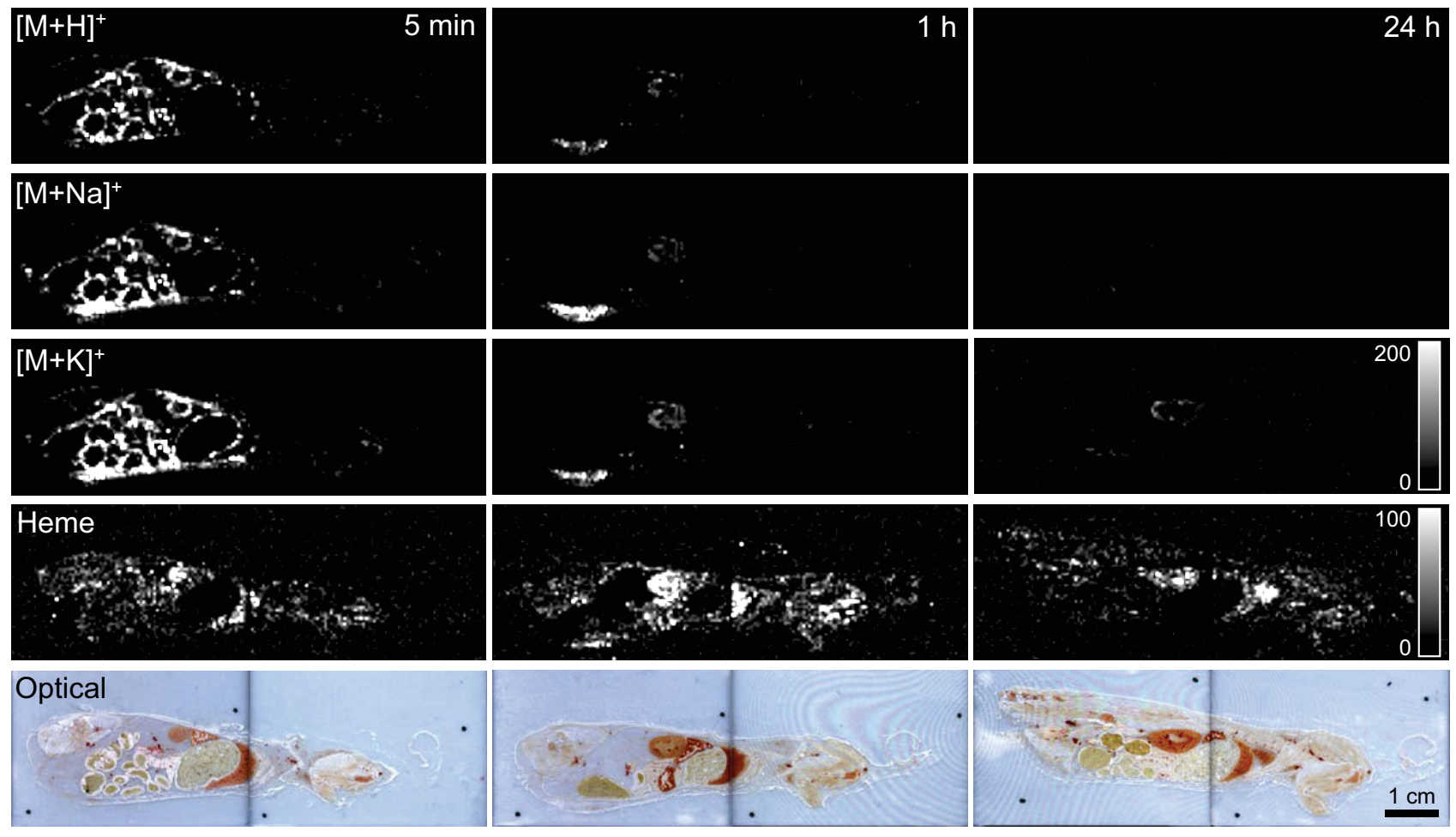

Figure 3. Top three rows: Whole-body distribution of $\beta$ peptide 1 measured by MALDI MSI after i.v. dosing. The peptide is slowly excreted through the kidney. The heme signal was evaluated to control the matrix deposition and the pictures of the uncoated sections are shown for reference. 


\section{Conclusion}

It is obvious that the results reported here do not present a full evaluation of the $\beta$-peptide and its metabolite distribution in the animals. Tissue-dependent signal suppression was not accounted for, and there were no internal standards added for quantification. However this study does allow an extremely quick and cost efficient evaluation of the compound behavior in the animals, confirming that $\beta$-peptides are stable and distribute specifically in the tissues in vivo. While traditional autoradiography would have taken over 1 wk to deliver a result, mass spectrometry has provided relevant data after just a single day. This is the first example in which an i.v. administered peptide has been used for MS imaging.

\section{Acknowledgments}

The authors would like to thank Rene Amstutz for supporting this work, and Jörg Seebach and Karl Lang for providing the transgenic mice. JG also thanks the New Zealand Foundation for Research Science and Technology for financial support.

\section{References}

1. Caprioli, R. M.; Farmer, T. B.; Gile, J. Molecular Imaging of Biological Samples: Localization of Peptides and Proteins Using MALDI-TOF MS. Anal. Chem. 1997, 69, 4751-4760.
2. Pierson, J.; Norris, J. L.; Aerni, H. R.; Svenningsson, P.; Caprioli, R. M.; Andren, P.E. Molecular Profiling of Experimental Parkinson's Disease: Direct Analysis of Peptides and Proteins on Brain Tissue Sections by MALDI Mass Spectrometry. J. Proteome Res. 2004, 3, 289-295.

3. Caprioli, R. M.; Farmer, T. B.; Zhang, H.; Stoeckli, M. Molecular imaging of biological samples by MALDI MS. Proceedings of the 214th ACS National Meeting, Book of Abstracts; Las Vegas, NV, September, 1997; p ANYL-113.

4. Stoeckli, M.; Staab, D.; Staufenbiel, M.; Wiederhold, K. H.; Signor, L. Molecular Imaging of Amyloid $\beta$ Peptides in Mouse Brain Sections Using Mass Spectrometry. Anal. Biochem. 2002, 311, 33-39.

5. Stoeckli, M.; Staab, D.; Schweitzer, A. Compound and Metabolite Distribution Measured by MALDI Mass Spectrometric Imaging in Whole-Body Tissue Sections. Int. J. Mass Spectrom. 2007, 260, 195-202.

6. Khatib-Shahidi, S.; Andersson, M.; Herman, J. L.; Gillespie, T. A.; Caprioli, R. M. Direct Molecular Analysis of Whole-Body Animal Tissue Sections by Imaging MALDI Mass Spectrometry. Anal. Chem. 2006, 78, 6448-6456.

7. Seebach, D.; Beck, A. K.; Bierbaum, D. J. The World of $\beta$ - and $\gamma$-Peptides Comprised of Homologated Proteinogenic Amino Acids and Other Components. Chem. Biodiversity 2004, 1, 1111-1239.

8. Nunn, C.; Rueping, M.; Langenegger, D.: Schuepbach, E.; Kimmerlin, T. Micuch, P.; Hurth, K.; Seebach, D.; Hoyer, D. $\beta(2) / \beta(3)$-Di- and $\alpha / \beta(3)-$ Tetrapeptide Derivatives as Potent Agonists at Somatostatin SST(4) Receptors. Naunyn-Schmiedebergs Arch Pharmacol 2003, 367, 95-103.

9. Frackenpohl, J.; Arvidsson, P. I.; Schreiber, J. V.; Seebach, D. The Outstanding Biological Stability of $\beta$ - and $\gamma$-Peptides Toward Proteolytic Enzymes: An in Vitro Investigation with Fifteen Peptidases. Chem. Biochem. 2001, 2, 445-455.

10. Weiss H. M.; Wirz B.; Schweitzer A.; Amstutz R.; Rodriguez-Perez M. I.; Andres H.; Metz Y.; Gardiner J.; Seebach D. ADME-Investigations of Unnatural Peptides: Distribution of a ${ }^{14} \mathrm{C}$-labeled $\beta-^{3}$-Octa-Arginine in Rats. Chem. Biodivers 2007, 4, 1413-1437.

11. Schreiber, J. V.; Quadroni, M.; Seebach, D. Sequencing of $\beta$-Peptides by Mass Spectrometry. Chimia 1999, 53, 621-626.

12. Hook, D. F.; Bindschadler, P.; Mahajan, Y. R.; Sebesta, R.; Kast, P.; Seebach, D. The Proteolytic Stability of "Designed" $\beta$-Peptides Containing $\alpha$-peptide-bond mimics and of mixed $\alpha, \beta$-peptides: Application to the Construction of MHC-Binding Peptides. Chem. Biodiversity 2005, 2, 591-632.

13. Ullberg, S. The Technique of Whole-Body Autoradiography: Cryosectioning of Large Specimens. In: Science Tools; Alvfeldt O., Ed.; Science Tools LKB-Producter AB: Stockholm, Sweden, 1977. 